\title{
Impact of Age, CYP2C9 Genotype and Concomitant Medication on the Rate of Rise for Prothrombin Time During the First 30 Days of Warfarin Therapy
}

\author{
Russell A. Wilke, MD, PhD; Richard L. Berg, MS; Humberto J. Vidaillet, MD; \\ Michael D. Caldwell, MD, PhD; James K. Burmester, PhD and Michael A. Hillman, MD, MBA
}

\begin{abstract}
Objectives: To characterize the impact of several important clinical variables on the rate of anticoagulation during warfarin initiation (i.e., the first 30 days).

Design: Retrospective study.

Setting: An anticoagulation service of a large horizontally integrated, multispecialty group practice in central and northern Wisconsin.
\end{abstract}

Participants: Patients with sufficient laboratory data obtained during the initiation phase of warfarin treatment.

Methods: Patients were consented and genotyped for cytochrome P450 (CYP) 2C9 polymorphisms. Anticoagulation laboratory data were then electronically abstracted and fitted to a logistic growth model. Rate of anticoagulation was compared between groups.

Results: During warfarin initiation, the mean slope for rise in International Normalized Ratio (INR) of prothrombin time was significantly associated with age $(p=0.03, n=166)$. Because a relationship between diabetes and warfarin dosing has been suggested previously, we assessed the impact of this comorbidity in our model as well. Diabetes showed relatively little impact, but concomitant treatment with an anti-diabetic sulfonylurea medication was associated with an increase in slope $(3$-fold, $p<0.05)$. Since this drug interaction may occur at the level of CYP2C9, we also assessed the impact of CYP2C9 genotype in our model. The impact of CYP2C9 genotype was marginally significant $(p=0.119$, non-pooled dataset; $\mathrm{p}=0.053$, data pooled for CYP2C9 $* 2 / * 2$, $* 2 / * 3$ and $* 3 / * 3$ ).

Conclusions: Age and concomitant sulfonylurea therapy alter the rate of anticoagulation during the first 30 days of warfarin therapy.

Keywords: Pharmacogenetics, Pharmacokinetics, Drug interactions, Logistic modeling, Prothrombin time

$\mathrm{C}$

linical trials have unequivocally demonstrated the efficacy of warfarin for preventing and treating thromboembolic disease. ${ }^{1,2}$ In the context of atrial fibrillation, this agent reduces the risk of ischemic stroke by
$65 \% .^{3,4}$ If left untreated, patients with atrial fibrillation typically have a mortality risk 2.5 times higher than anticoagulated controls. ${ }^{5}$ Despite compelling clinical indication, not all patients requiring stroke prophylaxis receive warfarin anticoagulation. ${ }^{6}$ Although the reasons for this discrepancy are complicated, a variety of scalable clinical 
factors appear to influence the decision-making process when a patient and their physician assess the risks and benefits of anticoagulation. ${ }^{7,8}$ These factors include the patient's unique risk of thromboembolism (based on comorbidities), appropriate concern regarding the narrow therapeutic index of warfarin and the potential severity of warfarin-related adverse bleeding events.

We recently characterized the relative impact of clinical covariates (including age, gender, body composition, comorbidity and concomitant medication) on stable maintenance warfarin dose, in the context of cytochrome P450 (CYP) 2C9 genotype, in a large retrospective patient cohort followed regularly in our outpatient anticoagulation clinic. ${ }^{9}$ Interestingly, these data revealed a complex multivariate interaction between diabetes and genotype, with respect to overall final maintenance dose of warfarin. ${ }^{9}$ Although diabetes is known to be associated with hypercoagulable states, the pathogenetic mechanism appears to involve platelet dysfunction rather than a disruption of clotting factor homeostasis.4,10-18 Other factors (e.g., comorbidity or concomitant medication) are therefore likely to contribute to this interaction.

The majority of warfarin-related adverse bleeding events occur during the first 30 days of warfarin therapy. ${ }^{8,19} \mathrm{We}$ therefore opted to extend our analysis of the original retrospective cohort to gain additional mechanistic insight into the clinical factors associated with rate of warfarin anticoagulation, specifically during the period of drug initiation. Using a strategy that employs electronic data abstraction and mathematical modeling, we now report the impact of age, CYP2C9 genotype and concomitant medication on the rate of warfarin anticoagulation.

\section{Methods}

Study design

We utilized electronic data abstraction to retrospectively query the clinical medical records of the anticoagulation population characterized previously in our cohort study of warfarin maintenance dose. ${ }^{9}$ Recruitment strategies have been summarized below, along with a specific description of inclusion and exclusion criteria. The goal of the present study was to identify a subset of patients with sufficient laboratory data during the initiation phase of warfarin treatment for use in modeling and analysis of factors influencing the initial rate of anticoagulation. Consent was obtained according to institutional guidelines. The genotyping methods were published previously. ${ }^{9}$

\section{Patient recruitment}

Patients were recruited from the anticoagulation service of a large horizontally integrated, multispecialty group practice in central and northern Wisconsin. This service is staffed by registered nurses using physician-approved protocols to provide a standardized approach to patient assessment, warfarin dosage, laboratory testing and medical record documentation while in communication with the anticoagulation medical director or the patient's referring provider. Patients were excluded from this study if they were known to have underlying conditions that may influence drug dosage, such as cancer, renal or hepatic insufficiency, or heart failure. Conditions were identified based on disease-specific clinical and/or laboratory indicators, such as increased serum creatinine in the case of renal insufficiency and increased circulating transaminase levels in the case of hepatic insufficiency, as well as the diagnostic codes assigned.

Eligible patients were recruited and enrolled after providing informed consent according to an institutional protocol approved by the Institutional Review Board of Marshfield Clinic Research Foundation. Six hundred eligible patients were approached; 453 agreed to participate. Medical charts, anticoagulation data and prescribed medications were abstracted from the clinical records of all 453 consenting patients, and blood samples were collected for genotype analysis. Investigators performing the DNA analysis were blinded to any clinical data. The genotyping data was published previously. ${ }^{9}$

\section{Electronic abstraction of clinical laboratory data}

A computer program was constructed to abstract the International Normalized Ratios (INRs) for prothrombin time during the first 30 days of warfarin therapy. Since some patients from the original cohort of 453 may have initiated warfarin at an outside institution or their initial laboratory data were otherwise unavailable, the overall number of patients in the final electronically abstracted dataset was less than the original 453 .

Only patients who started warfarin after 1995 were considered. Prior to this date, adequate INR data were available inconsistently in the electronic medical record. This reduced the dataset from 453 to 354 . A selection algorithm was then used to flag patients who had a normal pre-treatment INR (value $\leq 1.5$ ) and four or more INR results available electronically within the initial 30-day exposure period. A total of 236 patients met these selection criteria and were considered for additional detailed medical record review. Of these 236 records, dosing data was available for 195 patients.

Data for these 195 patients were abstracted and entered into a study database. All available INR results were considered through 30 days following initiation of warfarin therapy. For any given patient, the data string was truncated if an INR decline of $33 \%$ or more was identified. In total, 1,235 INR test results were modeled with a median of 6 results per patient.

\section{Kinetic modeling}

The relationship between the initiation of multiple oral dosing of warfarin and the rise in INR in any given patient is not direct and is potentially influenced by a number of genetic and environmental factors. ${ }^{20}$ Clinically there is a lag between 


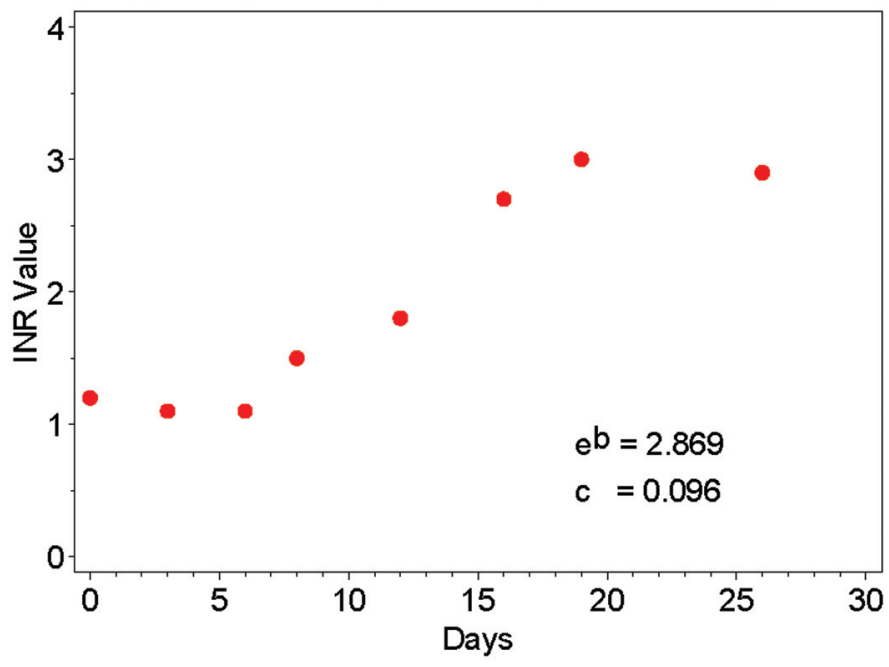

Figure 1. Example of electronically abstracted laboratory results (prothrombin time, International Normalized Ratio [INR]) for one representative patient.

the first pulses of oral warfarin and the beginning of a rise in INR after which the INR rises more rapidly. A sigmoidal dose-response curve best describes this behavior and, therefore, a logistic function was used to model each subject's initial response to warfarin. This relationship was found to be consistent with the pattern observed in most subjects (figure 1). The following logistic growth model was applied. ${ }^{21}$

$$
\mathrm{INR}=1+\left(0.1+0.1 e^{\mathrm{b}}\right) /\left(1.0+e^{\mathrm{b} / e^{\mathrm{c}} \text { days }}\right) \quad \text { Equation } 1
$$

By definition, the INR is constrained to be 1.1 (our observed median) on the day of initiation (day 0), and the INR increases over time to an asymptote represented by $1.1+0.1 e^{\mathrm{b}}$. Primary interest was in the initial rate of rise (slope). Analysis of the slope was therefore restricted to a time domain limited by the inflection point (b/c) (figure 2). The slope within this time domain can be expressed in terms of the model parameters as follows:

$$
\text { Slope-to-inflection }=0.05 \mathrm{c}\left(\mathrm{e}^{\mathrm{b}}-1.0\right) / \mathrm{b} \quad \text { Equation } 2 .
$$

\section{Statistical Analysis}

The model was applied separately to data for 195 patients and converged (i.e., the statistical software was able to calculate parameter estimates) for 166 individuals (85\%). Various clinical factors were then evaluated for possible association with the slope-to-inflection. The Spearman rank correlation was used to characterize associations among quantitative variates, and the Kruskal-Wallis test was used for comparisons among groups. Analysis of covariance (ANCOVA) was used to further evaluate factors while adjusting for dose after a log transformation to help normalize the skewed distribution of the slope estimates. Warfarin dose was incorporated in the ANCOVA models using two separate terms: (1) initial dose for the first day on drug and (2) average dose over the remaining 30-day study period. Results were deemed significant at the $5 \%$ level (i.e., $\mathrm{p}<0.05$ ).

\section{Results}

Impact of age

The demographics of the 166 patients with model results are shown in table 1 . The gender distribution was 77 females (46\%) and 89 males (54\%), and the distribution of clinical comorbidity and indication for warfarin therapy were similar to those for the entire population. ${ }^{9}$ The overall median slope was 0.21 INR units per day (median inflection point 5.0 days). Clinical variables were first tested for association with slope in univariate analyses. Age, initial dose and mean dose were all significantly correlated with this slope parameter (table 1).

\section{Impact of concomitant medication}

Based upon our previously reported association between maintenance warfarin dose and diabetes, we also tested the rate of anticoagulation (warfarin initiation) for association with the presence of diabetes and for association with the concomitant use of a sulfonylurea medication. The results are shown in table 2. Only concomitant sulfonylurea medication was found to have a significant association with slope. The INR was found to rise faster in patients using this class of medications (3-fold increase in the median). This observation was true even relative to the other 16 patients with diabetes who were not using sulfonylurea medication $(\mathrm{p}=0.014)$.

Most sulfonylurea medications are metabolized by CYP2C9. Due to the substantial impact of sulfonylureas, the impact of other medications known to interact with CYP2C9 was assessed (table 3). For this analysis, medications were categorized as (A) transcriptional inducer, (B) mechanism-based inhibitor or (C) competitive substrate, according to a nationally recognized web-based resource for drug interactions (http://medicine.iupui.edu/flockhart/). Mean INR slopes were then compared between groups. In situations where patients were taking more than one of these medications, patients were assigned to the category with highest potential for transcriptional impact on the CYP2C9

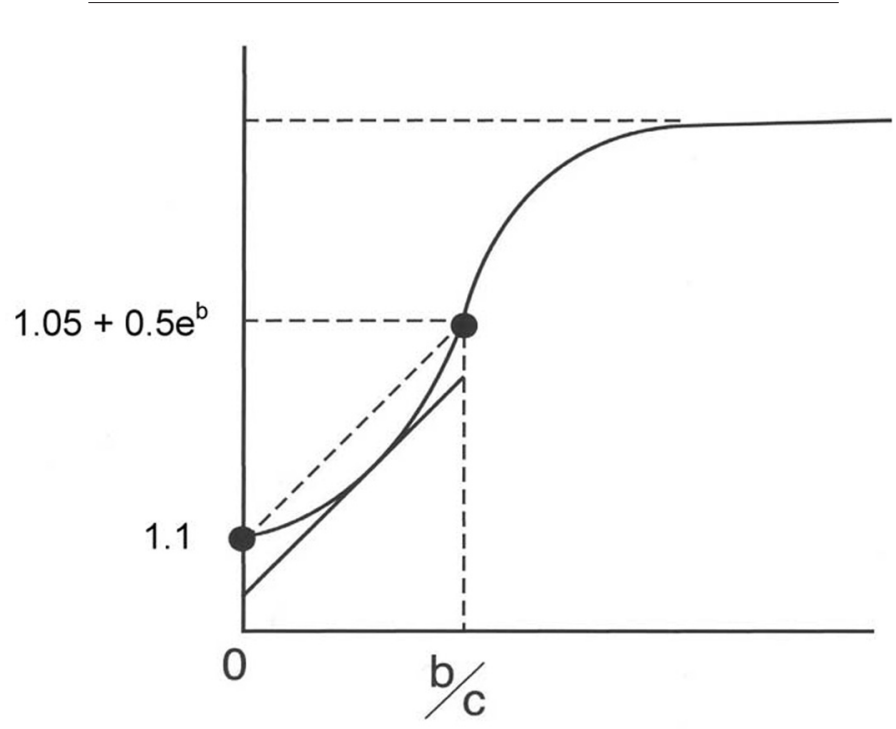

Figure 2. Plot exhibiting the arc tangent that was used to determine slope of the anticoagulation response curve from time zero to the inflection point (b/c). 
Table 1. Patient demographics and correlation with slope.

\begin{tabular}{|c|c|c|c|c|c|}
\hline & Number & Mean & S.D. & $\begin{array}{l}\text { Spearman } \\
\text { Correlation } \\
\text { Coefficient }\end{array}$ & p-value \\
\hline Age (years) & 166 & 68.4 & 11.7 & 0.18 & 0.031 \\
\hline Weight (kg) & 163 & 86.9 & 21.5 & -0.04 & 0.657 \\
\hline Height (cm) & 156 & 170.0 & 10.9 & -0.08 & 0.293 \\
\hline $\operatorname{BSA}\left(m^{2}\right)$ & 156 & 1.97 & 0.26 & -0.05 & 0.556 \\
\hline Initial dose (mg) & 166 & 6.2 & 2.6 & 0.32 & $<0.001$ \\
\hline $\begin{array}{c}\text { Mean dose }(\mathrm{mg}) \text { days } \\
2 \text { through } 28\end{array}$ & 166 & 4.8 & 1.8 & -0.33 & $<0.001$ \\
\hline
\end{tabular}

BSA: body surface area; S.D.: standard deviation

gene. ${ }^{9}$ When analyzed according to category, medications interacting with CYP2C9 showed no association with the initial rate of warfarin anticoagulation $(p=0.547)$. In this analysis, the most commonly observed classes of CYP2C9 inhibitors were proton pump inhibitors ( $n=7$ subjects), fibric acid derivatives ( $\mathrm{n}=6$ subjects) and serotonin selective reuptake inhibitors ( $\mathrm{n}=3$ subjects). The most commonly observed classes of CYP2C9 substrates were cyclooxygenase-II inhibitors ( $\mathrm{n}=9$ subjects), angiotensin-II receptor antagonists $(\mathrm{n}=9$ subjects $)$ and sulfonylureas $(\mathrm{n}=6$ subjects). Individual drug effects were not tested.

Impact of genotype

We also attempted to gain insight into the potential impact of congenital variation in CYP2C9 enzyme activity. In our study population, most of the genetic variation in the CYP2C9 gene can be attributed to either CYP2C9*2 or CYP2C9*3 with approximately one-third of these patients expressing at least one copy of these variant alleles. ${ }^{9}$ The initial anticoagulation rate in our model is presented for each allele group in table 4. Little association was detected between CYP2C9 genotype and slope. Power was limited, however, with only 59 patients in the non-wild type genotype.

Post hoc adjustment for physician prescribing practices Lastly, analyses adjusting for dose were used to control for differences in warfarin dosing strategies. Although the initial warfarin dose was positively correlated with rate of rise of INR, mean dose for the remainder of the 30-day period was negatively correlated (table 1). The combination of these two terms may reflect common discrepancies between the initial dose and the optimal dose as determined over time. Therefore, key comparisons were subsequently adjusted for both dosing terms (table 5). To control for genotype, this analysis was conducted only on patients expressing the homozygous wild type genotype (CYP2C9*1/*1; n=107).

Table 2. Analysis of slope by gender, diabetes and sulfonylurea co-medication.

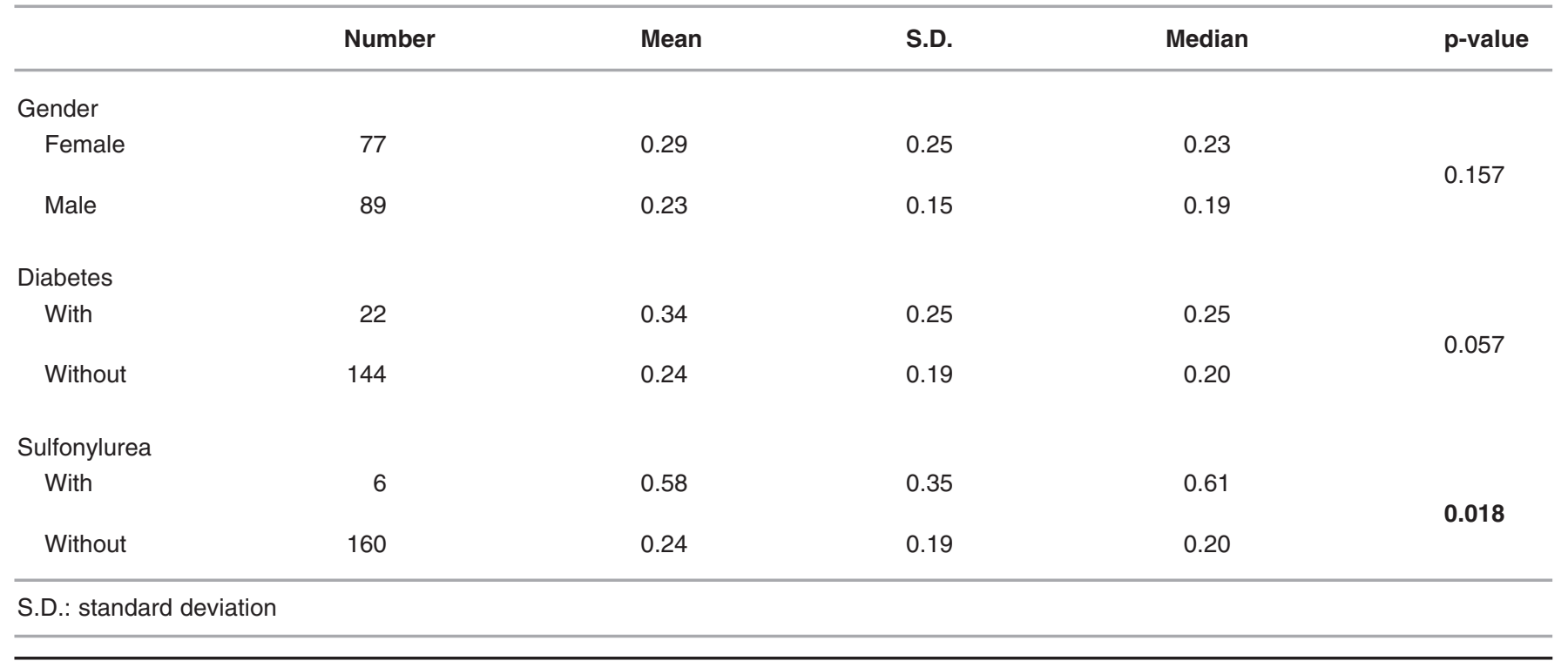


Table 3. Analysis of INR slope by CYP2C9 co-medication interaction category. *

\begin{tabular}{lcccc}
\hline Interaction Category & Number & Mean & S.D. & Median \\
\hline CYP2C9 inducer & 2 & 0.44 & 0.28 & 0.44 \\
CYP2C9 inhibitor & 21 & 0.23 & 0.15 & 0.16 \\
CYP2C9 substrate & 25 & 0.34 & 0.28 & 0.23 \\
No CYP2C9 medications & 118 & 0.24 & 0.19 & 0.21 \\
\hline
\end{tabular}

* $\mathrm{p}=0.547$ : Group comparison excluding two patients on CYP2C9 inducer medications. INR: International Normalized Ratio; S.D.: standard deviation

Using this approach, the association with age was attenuated after the data were adjusted for dose (table 5). This is consistent with the fact that physicians tend to use lower initial warfarin doses in older patients $(\mathrm{p}=0.011$, data not shown). Conversely, the association with sulfonylureas appeared stronger when the data were adjusted for dose suggesting, in general, that physicians had not considered the potential kinetic impact of this drug-drug interaction when initiating warfarin therapy in diabetic patients.

\section{Discussion}

We previously demonstrated the presence of a multivariate association between the maintenance dose of warfarin and the following clinical variables: age, gender, body size, comorbidity, concomitant medication and CYP2C9 genotype. ${ }^{9}$ The relationship between warfarin dose and age, in particular, has long been understood in the context of stable maintenance dose. ${ }^{22-24}$ The results generated by the current study further our understanding of this relationship by extending it back to the period of warfarin initiation (i.e., prior to determination of the maintenance dose).

This association between age and initial rate of anticoagulation is particularly important, since data have clearly documented that the risk of serious warfarin-related bleeding complications increases with age. ${ }^{25}$ Although our initial dataset revealed that age was highly associated with mean INR slope, this association was attenuated when the data were adjusted for warfarin dose (Post Hoc, table 5). As stated earlier, the most likely interpretation for this observation would be that physicians had appropriately considered age when choosing an initial warfarin dose.

The active enantiomer of warfarin (S-warfarin) is metabolized primarily by CYP2C9. An unequivocal association has been shown between CYP2C9 gene polymorphisms and warfarin-related clinical outcomes. ${ }^{26}$ The relationship between CYP2C9 gene polymorphisms and warfarin maintenance dose has since been characterized in the context of a variety of salient clinical covariates. $9,27,28$ More recently, others have suggested that CYP2C9 genotype may impact warfarin initiation dose as well. ${ }^{29}$ Therefore, it is odd that we did not observe a more robust relationship between CYP2C9 genotype and rate of anticoagulation in the current study. One potential explanation includes a lack of statistical power with respect to patients expressing variant alleles $(n=166$ for the entire cohort, $\mathrm{n}=107$ for homozygous wild type, and $\mathrm{n}=59$ for the subset expressing at least one variant CYP2C9 allele). Larger, prospective studies are needed to clarify whether CYP2C9 genotype alters the initial rate of warfarin anticoagulation. ${ }^{30}$

Like warfarin, most sulfonylureas are also metabolized by CYP2C9. Sulfonylurea use is known to inhibit the metabolism of other drugs in a competitive fashion, 31,32 and sulfonylureas are often used as probe substrates for CYP2C9 activity. ${ }^{33,34}$ The potential for a warfarin-sulfonylurea drug interaction is therefore substantial. Data generated in the

Table 4. Analysis of INR slope by CYP2C9 genotype. ${ }^{\dagger}$

\begin{tabular}{ccccc}
\hline Genotype & Number & Mean & S.D. & Median \\
\hline$* 1 /{ }^{*} 1$ & 107 & 0.26 & 0.24 & 0.19 \\
$* 1 /{ }^{*} 2$ & 35 & 0.21 & 0.09 & 0.12 \\
$* 1 /{ }^{*} 3$ & 17 & 0.25 & 0.14 & 0.25 \\
$* 2 /{ }^{*} 2$ & 5 & 0.32 & - & 0.29 \\
$* 2 /{ }^{*} 3$ & 1 & 0.56 & - & 0.56 \\
$* 3 /{ }^{*} 3$ & 1 & 0.68 &
\end{tabular}

${ }^{\dagger} \mathrm{p}=0.119$ comparing all genotypes, $\mathrm{p}=0.053$ for comparison pooling ${ }^{*} 2 /{ }^{*} 2,{ }^{*} 2 /{ }^{*} 3$, and ${ }^{*} 3 /{ }^{*} 3$, and $p=0.441$ for comparison excluding ${ }^{*} 2 /{ }^{*} 2,{ }^{*} 2 /{ }^{*} 3$, and ${ }^{*} 3 /{ }^{*} 3$ due to small numbers. INR: International Normalized Ratio; S.D.: standard deviation 
Table 5. Estimates of relative INR slope adjusting for warfarin dose.*

\begin{tabular}{lllcl}
\hline Clinical Factor & Slope Ratio & 95\% Confidence Limits & p-value & $\begin{array}{l}\text { Full Model }^{\dagger} \\
\mathbf{p} \text {-value }\end{array}$ \\
\hline Age (years) & 1.003 & $0.990-1.017$ & 0.624 & 0.779 \\
Sulfonylurea & 3.727 & $1.914-7.257$ & $<0.001$ & 0.001 \\
Diabetes & 1.505 & $0.974-2.326$ & 0.065 & 0.733 \\
\hline
\end{tabular}

${ }^{*}$ Results from analysis of covariance models with a single clinical factor and warfarin dose (initial and subsequent mean) in patients with the ${ }^{*} 1 /{ }^{*} 1$ genotype only. Estimates represent the multiplicative effect of the factor and, for age, the effect is relative to a 1-year increase in age. tResults including age, diabetes, and sulfonylurea simultaneously in the model.

INR = International Normalized Ratio.

current study reveal that the association between sulfonylurea use and rate of warfarin anticoagulation is statistically significant $(\mathrm{p}=0.018)$. Since the effect size for this relationship is quite large (i.e., sulfonylureas were associated with a 3-fold increase in the median INR slope), physicians may want to consider prescribing a reduced starting dose when initiating warfarin therapy in their diabetic patients requiring anticoagulation. Although our results were significant even upon adjustment for other factors, this evidence is limited by the small number using sulfonylurea medication (6 patients), and we must acknowledge the possibility that other unmeasured differences in that group may be involved. Furthermore, since no significant association was observed between slope and CYP2C9 substrates (as a class), it is conceivable that the interaction observed between slope and sulfonylureas may be independent of CYP2C9. Larger studies are needed to clarify the nature of this interaction.

Currently, efforts are being made to standardize the process of model-based warfarin dosing. ${ }^{30,35-37}$ Rational dosing models that include a combination of genetic and clinical information are likely to lead to improved physician confidence in situations requiring the use of warfarin anticoagulation.

\section{Acknowledgments}

The authors would like to thank Carla Rottscheit for her work with the study database, and the Marshfield Clinic Research Foundation for providing assistance in the preparation of this manuscript through the services of Graig Eldred, Linda Weis and Alice Stargardt.

\section{References}

1. Corley SD, Epstein AE, DiMarco JP, Domanski MJ, Geller N, Greene HL, Josephson RA, Kellen JC, Klein RC, Krahn AD, Mickel M, Mitchell LB, Nelson JD, Rosenberg Y, Schron E, Shemanski L, Waldo AL, Wyse DG; AFFIRM Investigators. Relationships between sinus rhythm, treatment, and survival in the Atrial Fibrillation Follow-Up Investigation of Rhythm Management (AFFIRM) Study. Circulation 2004;109:1509-1513.
2. Kearon C, Ginsberg JS, Kovacs MJ, Anderson DR, Wells P, Julian JA, MacKinnon B, Weitz JI, Crowther MA, Dolan S, Turpie AG, Geerts W, Solymoss S, van Nguyen P, Demers C, Kahn SR, Kassis J, Rodger M, Hambleton J, Gent M; Extended Low-Intensity Anticoagulation for Thrombo-Embolism Investigators. Comparison of low-intensity warfarin therapy with conventional-intensity warfarin therapy for long-term prevention of recurrent venous thromboembolism. N Engl J Med 2003;349:631-639.

3. Linkins LA, Choi PT, Douketis JD. Clinical impact of bleeding in patients taking oral anticoagulants for venous thromboembolism. Ann Intern Med 2003;139:893-900.

4. Schulman S. Clinical practice. Care of patients receiving long-term anticoagulant therapy. N Engl J Med 2003;349:675-683.

5. Singer DE, Albers GW, Dalen JE, Go AS, Halperin JL, Manning WJ. Antithrombotic therapy in atrial fibrillation: the Seventh ACCP Conference on Antithrombotic and Thrombolytic Therapy. Chest 2004;126:429S-456S.

6. Vidaillet H, Granada JF, Chyou PH, Maassen K, Ortiz M, Pulido JN, Sharma P, Smith PN, Hayes J. A population-based study of mortality among patients with atrial fibrillation or flutter. Am J Med 2002;113:432-435.

7. Bungard TJ, Ghali WA, Teo KK, McAlister FA, Tsuyuki RT. Why do patients with atrial fibrillation not receive warfarin? Arch Intern Med 2000;160:41-46.

8. Marshfield Medical Research and Education Foundation. Assessing impact of organizational interventions Marshfield Clinic's Coumadin Clinic Evaluation: Final Report. Submitted to Agency for Healthcare Research and Quality (AHRQ), 13 May, 2001.

9. Hillman MA, Wilke RA, Caldwell MD, Berg RL, Glurich I, Burmester JK. Relative impact of covariates in prescribing warfarin according to CYP2C9 genotype. Pharmacogenetics 2004;14:539-547.

10. Imperatore G, Cadwell BL, Geiss L, Saadinne JB, Williams DE, Ford ES, Thompson TJ, Narayan KM, Gregg EW. Thirty-year trends in cardiovascular risk factor levels among US adults with diabetes: National Health and Nutrition Examination Surveys, 1971-2000. Am J Epidemiol 2004;160:531-539.

11. Aso Y, Matsumoto S, Fujiwara Y, Tayama K, Inukai T, Takemura Y. Impaired fibrinolytic compensation for hypercoagulability in obese patients with type 2 diabetes: association with increased plasminogen activator inhibitor-1. Metabolism 2002;51:471-476.

12. Knobl P, Schernthaner G, Schnack C, Pietschmann P, Griesmacher A, Prager R, Muller M. Thrombogenic factors are related to urinary albumin excretion rate in type 1 (insulin-dependent) and type 2 (non-insulin-dependent) diabetic patients. Diabetologia 1993;36:1045-1050.

13. Vinik AI, Erbas T, Park TS, Nolan R, Pittenger GL. Platelet dysfunction in type 2 diabetes. Diabetes Care 2001;24:1476-1485. 
14. Yazbek N, Bapat A, Kleiman N. Platelet abnormalities in diabetes mellitus. Coron Artery Dis 2003;14:365-371.

15. Arjomand H, Roukoz B, Surabhi SK, Cohen M. Platelets and antiplatelet therapy in patients with diabetes mellitus. J Invasive Cardiol 2003;15:264-269.

16. Ferroni P, Basili S, Falco A, Davi G. Platelet activation in type 2 diabetes mellitus. J Thromb Haemost 2004;2:1282-1291.

17. Sadler JE. Medicine: $\mathrm{K}$ is for koagulation. Nature 2004;427:493-494.

18. Kamali F, Edwards C, Butler TJ, Wynne HA. The influence of (R)- and (S)-warfarin, vitamin $\mathrm{K}$ and vitamin $\mathrm{K}$ epoxide on warfarin anticoagulation. Thromb Haemost 2000;84:39-42.

19. Levine MN, Raskob G, Beyth RJ, Kearon C, Schulman S. Hemorrhagic complications of anticoagulant treatment: the Seventh ACCP Conference on Antithrombotic and Thrombolytic Therapy. Chest 2004;126:287S-310S.

20. Shikata E, Ieiri I, Ishiguro S, Aono H, Inoue K, Koide T, Ohgi S, Otsubo K. Association of pharmacokinetic (CYP2C9) and pharmacodynamic (factors II, VII, IX, and X; proteins S and $\mathrm{C}$; and gamma-glutamyl carboxylase) gene variants with warfarin sensitivity. Blood 2004;103:2630-2635.

21. Ratkowsky DA. Nonlinear Regression Modeling. New York, NY: Marcel Dekker; 1983.

22. Desbiens NA. Deciding on anticoagulating the oldest old with atrial fibrillation: insights from cost-effectiveness analysis. J Am Geriatr Soc 2002;50:863-869.

23. Adams JN, Gautam PC. Anticoagulant therapy in elderly patients. J Clin Exp Gerontol 1992;14:183-196.

24. Wickramasinghe LS, Basu SK, Bansal SK. Long-term oral anticoagulant therapy in elderly patients. Age Ageing 1988;17:388-396.

25. Fang MC, Chang Y, Hylek EM, Rosand J, Greenberg SM, Go AS, Singer DE. Advanced age, anticoagulation intensity, and risk for intracranial hemorrhage among patients taking warfarin for atrial fibrillation. Ann Intern Med 2004;141:745752.

26. Higashi MK, Veenstra DL, Kondo LM, Wittkowsky AK, Srinouanprachanh SL, Farin FM, Rettie AE. Association between CYP2C9 genetic variants and anticoagulation-related outcomes during warfarin therapy. JAMA 2002;287:1690-1698.

27. Wadelius M, Sorlin K, Wallerman O, Karlsson J, Yue QY, Magnusson PK, Wadelius C, Melhus H. Warfarin sensitivity related to CYP2C9, CYP3A5, ABCB1 (MDR1) and other factors. Pharmacogenomics J 2004;4:40-48.

28. Gage BF, Eby C, Milligan PE, Banet GA, Duncan JR, McLeod HL. Use of pharmacogenetics and clinical factors to predict the maintenance dose of warfarin. Thromb Haemost 2004;91:87-94.

29. Peyvandi F, Spreafico M, Siboni SM, Moia M, Mannucci PM. CYP2C9 genotypes and dose requirements during the induction phase of oral anticoagulant therapy. Clin Pharmacol Ther 2004;75:198-203.

30. Hillman MA, Wilke RA, Yale SH, Vidaillet HJ, Caldwell MD, Glurich I, Berg RL, Schmelzer J, Burmester JK. A prospective, randomized pilot trial of CYP2C9 gene-based warfarin dosing. Clin Med Res 2005;3:137-145.

31. Kim KA, Park JY. Inhibitory effect of glyburide on human cytochrome p450 isoforms in human liver microsomes. Drug Metab Dispos 2003;31:1090-1092.

32. Rogers JF, Nafziger AN, Bertino JS Jr. Pharmacogenetics affects dosing, efficacy, and toxicity of cytochrome P450-metabolized drugs. Am J Med 2002;113:746-750.

33. Shadle CR, Lee Y, Majumdar AK, Petty KJ, Gargano C, Bradstreet TE, Evans JK, Blum RA. Evaluation of potential inductive effects of aprepitant on cytochrome P450 3A4 and 2C9 activity. J Clin Pharmacol 2004;44:215-223.
34. Hanatani T, Fukuda T, Onishi S, Funae Y, Azuma J. No major difference in inhibitory susceptibility between CYP2C9.1 and CYP2C9.3. Eur J Clin Pharmacol 2003;59:233-235.

35. You JH, Chan FW, Wong RS, Cheng G. The potential clinical and economic outcomes of pharmacogenetics-oriented management of warfarin therapy - a decision analysis. Thromb Haemost 2004;92:590-597.

36. Musana AK, Wilke RA. Gene-based drug prescribing: clinical implications of the cytochrome P450 genes. Wis Med J 2005;6:61-66.

37. Wilke RA, AK Musana, Weber WW. Cytochrome P450 gene-based drug prescribing, and factors impacting translation into routine clinical practice. Personalized Med 2005;2:213-224.

\section{Author Affiliations}

Russell A. Wilke, MD, PhD, Department of Internal

Medicine, Marshfield Clinic, and Center for Human

Genetics, Marshfield Clinic Research Foundation,

Marshfield, Wisconsin

Richard L. Berg, MS, Biostatistics and Bioinformatics Core, Marshfield Clinic Research Foundation, Marshfield, Wisconsin

Humberto J. Vidaillet, MD, Department of Cardiology, Marshfield Clinic, Marshfield, Wisconsin

Michael D. Caldwell, MD, PhD, Department of Surgery, Marshfield Clinic, Marshfield, Wisconsin

James K. Burmester, PhD, Center for Human Genetics, Marshfield Clinic Research Foundation, Marshfield, Wisconsin

Michael A. Hillman, MD, MBA, Care Management, Marshfield Clinic, Marshfield, Wisconsin 